\title{
Maximising the Effectiveness of Multi-Platform Networks in Health and Development: A Case Study of Be-Cause Health
}

Samuel Van Steirteghem ${ }^{1 *}$, Dikaios Sakellariou ${ }^{2 \dagger}$ and Karel Gyselinck ${ }^{3+}$

*Correspondence: samuel.vans@icloud.com

CrossMark

$\leftarrow$ Click for updates

These authors contributed equally this work.

'Scientific collaborator, Université Libre de Bruxelles (ULB), CHU Ambroise Paré, 2 boulevard Kennedy, 7000 Mons, Belgium.

${ }^{2}$ Senior Lecturer, Cardiff University, School of Healthcare Sciences, Eastgate House, Newport Road 35-43, Cardiff CF24 0AB, UK.

${ }^{3}$ Senior Health Advisor, Enabel Belgian development agency, Hoogstraat 147, 1000 Brussels, Belgium.

\begin{abstract}
Background: Networks have become a widely-used approach to address the complexity of issues around international health and health equity, and many types of networks have been described. The added value of networking is not straightforward and it should be documented. Be-Cause Health (BCH) is a unique, multistakeholder network linking the Belgian actors of the health and development sector, creating a partnership to support their commitment to equitable health. Consequently, $\mathrm{BCH}$ has very broad objectives with creative and dynamic outcomes. The aim of this study was to explore if the structure and process of the $\mathrm{BCH}$ network could be adapted to improve its effectiveness.

Methods: The overall framework of the project included a narrative literature review combined with qualitative semi-structured interviews. The literature review looked at the structure and process of networks and the means of evaluating network effectiveness. The results of this review were used to inform the interviews of key Be-Cause Health members.

Results: The reviewed articles illustrate the diversity of networking activities and the complexity of their evaluation, suggesting the use of participative evaluation methods to capture the intangible outcomes as experienced by the members themselves. The interviewees reported that the major benefits of their $\mathrm{BCH}$ membership were information sharing and connecting with peers. They felt the growth of the $\mathrm{BCH}$ network was mostly related to its culture of trust among members, to the inspiring leadership, to the concrete activities it could organise, to its flexible structure tailored to their needs, and to the support of the secretariat and to the embeddedness of the network in a wider institution with secured public funding. They identified a need for improved internal and external communication and for more concrete objectives of the working groups.
\end{abstract}

Conclusion: The $\mathrm{BCH}$ network is a unique response to the complex challenges of health equity and development. The outcomes of such complex networks cannot be measured with a simple quantitative method, and require participative methods of evaluation. There is no formula to predict the change of effectiveness that would result from a change of structure.

Keywords: Network, multi-stakeholder, Belgium, effectiveness, development, health, structure

\section{Background}

Equity in health and the principle of health for all imply dealing with challenges which involve multiple stakeholders and take place in complex environments. The creation of a network is usually considered an essential part of the process required to address these issues [1]. Alders et al. defined a network as "any group of individuals and organisations who, on a voluntary basis, organise themselves for a common purpose, exchanging

(c) 2019 Van Steirteghem et al; licensee Herbert Publications Ltd. This is an Open Access article distributed under the terms of Creative Commons Attribution License (http://creativecommons.org/licenses/by/3.0). This permits unrestricted use, distribution, and reproduction in any medium, provided the original work is properly cited. 
information or goods or implementing joint activities, in such a way that individual (or organisational) autonomy remains intact" [2]. Collaborating on a voluntary basis is the essence of networking activities, and creating a network allows its members to join their efforts and benefit from their partnership [3]. The goals of a network are major determinants of that network's characteristics. The membership criteria, the structure of the collaboration, and the funding of the network will all depend on what the network is aiming at [3].

The wide range of issues related to equitable health is such that many different types of networks have been created. Some of these are recurrent and guidelines have been published to support their creation and effective functioning [3-5]. However, most networks are a unique response to a unique situation. Creating a successful partnership and evaluating its effectiveness can be challenging [6]. Networks, especially multi-stakeholder ones, can be creative, benefitting from idea-sharing between their members; their outcomes, however, can be hard to measure. Network members join on a voluntary basis, but their networking activity can represent a considerable time investment. Their involvement in the network will depend on their perception of the benefit they get for the time invested. Funding is also necessary to run a network and the relevance of that financing must be evaluated [7]. The aim of this article is to explore the structural and procedural determinants of network effectiveness. Using the case study of the Belgian Be-Cause Health Network, we will focus on networks with multiple stakeholders and multiple objectives related to equitable health.

\section{The Be-Cause Health Network}

Be-Cause Health $(\mathrm{BCH})$ is a public funded network, hosted by the Institute of Tropical Medicine of Antwerp (ITM). BCH defines itself as "a pluralistic, open platform, providing a place for exchange and capitalisation of technical knowledge and scientific evidence on international health and development cooperation and its application in the field"[4]. Its mission is based on the right to health and health care for all. The network is accessible to any Belgian organisation or individual involved in international health and development sector, provided they agree with the vision and value statement of the network. It aims to promote collaboration and information exchange between its members and ultimately to improve their effectiveness in their actions for global health and health equity [8]. This network started in 2004 with a loose structure and open membership criteria. The $\mathrm{BCH}$ network thrived and included very diverse members (academic institutions, non-governmental organisations (NGOs), civil society organisations (CSOs), government bodies, private actors as well as individual members). After more than 10 years, the number of members has reached over 400 [8].

The current structure might not be adapted to the much larger network $\mathrm{BCH}$ has become. It is unclear how to deal with this increasing diversity of members, and how to stimulate the network dynamics, in order to generate broader creative outcomes rather than focusing exclusively on productivity. Specific questions need to be addressed around membership criteria, minimal involvement from the members or if their collaborative work could be improved by adapting the support from the leading and coordinating structures of the network.

As pointed out in the last external evaluation of $\mathrm{BCH}$, the need to adapt its rather loose structure and rules to this growth, without compromising the creativity and dynamism of the partnership, remains an open question [9]. The overall organisation of the network, more specifically the structure and processes that rule its activities, could play a significant role in the achievement of its goals [10].

\section{Methods}

The overall framework of the project included a narrative literature review combined with qualitative semi-structured interviews. The literature review looked at the structure and process of networks, to find examples that could be successfully transposed to $\mathrm{BCH}$. The means of evaluating the effectiveness of networks was also reviewed. The results from this review guided qualitative semi-structured interviews with some key members of $\mathrm{BCH}$, to collect their opinion on the structure of the network and how it could be evaluated. This project was approved by the ethical committee of the London School of Hygiene and Tropical Medicine (LSHTM) and by the steering committee of $\mathrm{BCH}$.

\section{Literature review}

The first objective of the literature review was to analyse the evidence on multi-stakeholder network structure and process, and how these could impact the effectiveness of the network. The second objective was to review the means of evaluation of network effectiveness.

The following questions were asked:

1. How can a multi-stakeholder health network be structured and organised?

2. How can the structure of a multi-stakeholder health network influence the effectiveness of that network, in terms of creative as well as productive outcomes?

3. How can the effectiveness of a multi-stakeholder health network be evaluated?

Three search concepts corresponding to these search questions were defined:

a. Multi-stakeholder health network structure.

b. Multi-stakeholder health network effectiveness.

c. Multi-stakeholder health network evaluation. The inclusion criteria were the following:

1. Articles describing networks for any of the following aspects:

a. The structure and organisation of networks, which can include one of the following: membership criteria, decision process, financial resources, representativeness, task distribution, control. 
b. How the structure of a network can affect its effectiveness.

c. How the effectiveness of a network can be evaluated.

2.Articles describing networks with different types of stakeholders with goals related to health equity and development.

3. Articles referring to health equity

4. Articles published in peer-reviewed journals or published by reputable organisations.

5.Articles published in English, French, or Flemish.

There was no restriction in date of publication.

Compiling the search strategy and running the search The search was mainly conducted through the use of free text terms in the following databases: MEDLINE, EMBASE, HMIC, GLOBAL HEALTH, and SCOPUS. The search started with the MEDLINE database through the OVID platform (Table 1). The search string was adapted to the other databases.

Table 1. Search string for Ovid Medline.

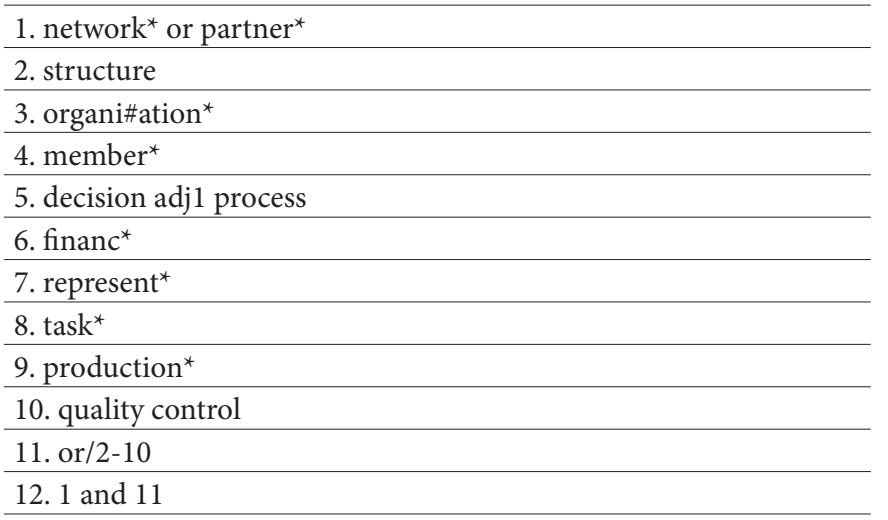

13. multi?platform or multi? party or multi?sector or multi?stakeholder

14. exploded "Global Health" or "Health" search heading/ or health.

15. 1 and 11 and 13 and 14

The symbols $\left({ }^{*}, \#, ?\right)$ and operators (and,or,adj) used in this search string are commontools used for Medline [11].

\section{Selection of documents}

Table 2 indicates the number of documents retrieved from each database. The selection of the documents was done in 2 stages according to the Centre for Review and Dissemination guidelines [12]. The first stage consisted in title and abstract screening, excluding clearly irrelevant publications (e.g. not about network structure nor evaluation). 39 publications were selected for the second stage, for which full text was obtained and managed through the Endnote ${ }^{\circ}$ software. All of these were read thoroughly to select the publications to be discussed. Although partly subjective, that selection process followed precise criteria:

1. Documents related to the network structure and its consequence on the effectiveness of the network.

2. Documents related to evaluation of networks.

3. Documents related to Health equity.
Table 2. Documents retrieved for each database (results of search strategy on March 20th, 2017).

\begin{tabular}{|c|c|c|}
\hline \multirow[t]{2}{*}{ Database } & \multicolumn{2}{|c|}{ Number of documents } \\
\hline & Retrieved & Selected \\
\hline Medline (Ovid) & 46 & 15 \\
\hline Embase (Ovid) & 75 & 23 \\
\hline HMIC (Ovid) & 2 & 2 \\
\hline Global Health (Ovid) & 19 & 6 \\
\hline Scopus (Elsevier) * & 36 & 15 \\
\hline Total $* *$ & - & 39 \\
\hline
\end{tabular}

* Use of proximity operator to reduce number of documents (strings 1 and 13 within 15 words)

${ }^{* *}$ After removing duplicates

4. Documents with recommendations transposable to the BCH network.

5. Documents describing networks with similarities with $\mathrm{BCH}$ : complex networks with multi-stakeholder membership, multi-platform structure, the contribution of members on a voluntary basis, active in health and development. 6. Documents of good quality according to the Critical Appraisal Skills Program (CASP) tools [13].

\section{Qualitative interviews}

Semi-structured interviews of members of $\mathrm{BCH}$ were performed. This type of interview was chosen to allow some flexibility to explore some aspects of $\mathrm{BCH}$ together with the interviewees [14].

\section{Recruitment}

We used a convenience sample of $\mathrm{BCH}$ network members. The secretariat of $\mathrm{BCH}$ sent a recruitment email to its members, inviting them to answer within ten working days if they considered participating. An informed consent form (IC) and a participant information sheet (PIS) were sent to those who answered the email. Before the interview, their signature on these documents was requested after checking if they had any concerns. As Sandelowski argues [15], sample size in qualitative research is guided by the aims of the study and the methodology; in this study, we wanted to critically discuss the literature review finding with the network members and gain an insight into their own perspectives, rather than develop an exhaustive understanding on the topic. Therefore, a small sample of five was deemed to be adequate. We were open to recruiting more participants, after a first round of five interviews, if there were contested issues, but that was not necessary.

\section{Data collection and analysis}

The interviews took place between May and June 2017 at the workplace of the interviewees and lasted approximately one hour. The interviews were semi-structured with open questions. The main results of the literature review were used as probing questions when relevant. The interviewees were encouraged 
to share their opinion on these results and develop possible other views. Each interview was recorded, transcribed, and the transcript was presented to the interviewee for review. Two interviews were done in English, two in Flemish and one in French, according to the preference of the interviewee.

Thematic analysis was used to analyse the data, following a stepwise approach of coding, as described by Durant and Chantler [14]. This coding process was aiming to describe the data in a meaningful manner [16]. Each transcript was read a number of times and margin notes were taken to identify what the participant was referring to. These notes were collated and analysed. An audit trail of the analytical thoughts was kept in the form of a diary. The margin notes were sorted into categories to develop a coding scheme. Each code was named and defined. The codes were refined by comparing the texts from all interviews, adding new categories and combining overlaps. A manual "cut and paste" technique was used to visualise the extracts supporting each category, allowing further refining of the coding scheme.

\section{Data quality}

The data collected were examined thoroughly to improve the quality of the analysis [14]. Reliability of the data was maximised by using a transparent and systematic data collection procedure: all steps were described in detail, all questions of the interview guide were covered, the recorded interview was precisely transcribed, and the transcript was sent to the interviewee to encourage further comment. Comparisons between cases and within the cases were performed, discussing contradictions and inconsistencies. Every effort was made to avoid imprinting ideas on the participants. The participants were selected through mailing by the secretariat of $\mathrm{BCH}$ to reduce the influence of existing connections between the interviewer and some members of $\mathrm{BCH}$.

\section{Results}

The results are divided into two sections. The first details the data of each article reviewed and the second presents the results of the interviews.

\section{Literature review}

Five articles met all of the inclusion criteria and were included in the review. Table 3 presents the findings of the literature review separately for each selected article and focused on the most relevant data to inform $\mathrm{BCH}$ on other networks' experiences which could guide their structural development.

\section{Results of the interviews}

The results of the interviews are presented by themes. Five themes were identified: perceived benefit from membership, overall organisation, membership criteria, control and financing of the network, and evaluation. The interviewees are referred to with pseudonyms. No other identifying information will be provided in order to protect their anonymity.

\section{Perceived benefit from membership}

For all participants, the main advantages were connecting with other members and sharing information. Concrete activities

Table 3. Summary findings of reviewed publications.

\begin{tabular}{|c|c|c|}
\hline References & Methods & Results \\
\hline Kendall 2012 [7] & $\begin{array}{l}\text { Literature review on capacity building for com- } \\
\text { munity health partnerships (groups of stake- } \\
\text { holders combining their resources to improve } \\
\text { health in local communities) }\end{array}$ & $\begin{array}{c}\text { Structured guidelines for development process of } \\
\text { network: } \\
\text { - } \quad \text { Identify barriers to collaboration among } \\
\text { - } \quad \text { Stimulate collaborative work by concrete } \\
\text { activities to increase the positive experi- } \\
\text { ence of members, the value they give to } \\
\text { their membership and their involvement } \\
\text { in the network } \\
\text { - Continuous evaluation process }\end{array}$ \\
\hline Keast and Mandell 2014[17] & $\begin{array}{l}\text { Qualitative research on case studies to analyse } \\
\text { the effect of a network's structure on its effec- } \\
\text { tiveness }\end{array}$ & $\begin{array}{l}\text { Classification of networks according to level of coop- } \\
\text { eration required to achieve the network's objectives. } \\
\text { Cooperative networks show low-level integration, } \\
\text { members being aware of each other but keeping } \\
\text { their own priorities, merely adapted for information } \\
\text { sharing. } \\
\text { Coordinative networks in which members put } \\
\text { resources together to reach more strategic objectives } \\
\text { but stay independent. } \\
\text { Collaborative networks, the most advanced stage of } \\
\text { collective work with members mutually interdepen- } \\
\text { dent. } \\
\text { Important determinants of effectiveness are ad- } \\
\text { equacy of the structure to the goals of the network, } \\
\text { identification of members to the network, external } \\
\text { context. }\end{array}$ \\
\hline
\end{tabular}


Continuation of Table 3.

\begin{tabular}{|c|c|c|}
\hline Woulfe et al. 2010 [18] & $\begin{array}{l}\text { Review of multi-sector partnerships to improve } \\
\text { population health, internal and external factors } \\
\text { of effectiveness. }\end{array}$ & $\begin{array}{cl}\text { Identification of key factors of network effectiveness: } \\
\text { - } & \text { Availability of sufficient resources and } \\
\text { - } & \text { their flexible use } \\
& \text { Clear goals, designed in participative man- } \\
\text { - } & \text { Eer and adapted to external context } \\
\text { - } & \text { Membership criteria including main actors } \\
& \text { but avoid inertia of too large networks } \\
\text { - } & \text { Transparent rules } \\
\text { - } & \text { Efficient conflict resolution }\end{array}$ \\
\hline Baker et al. 2012 [19] & $\begin{array}{l}\text { Comparison of } 25 \text { Active living by design } \\
\text { (ALbD) networks, all sharing the same goal of } \\
\text { stimulating physical exercise in their commu- } \\
\text { nity. Use of mixed methods. }\end{array}$ & 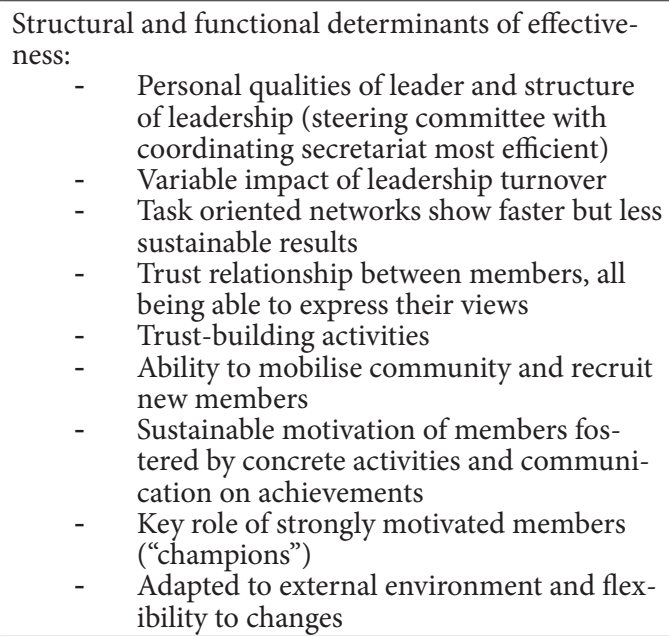 \\
\hline Church et al.2002[20] & $\begin{array}{l}\text { Evaluation model for networks from academic } \\
\text { research unit, combining questionnaire to net- } \\
\text { works, literature review and thoughtful analysis }\end{array}$ & $\begin{array}{l}\text { Recognition of very complex environment of net- } \\
\text { works' activity } \\
\text { Too many external factors to evaluate networks on } \\
\text { their productive outcomes. Subjective appraisal of } \\
\text { the network's contribution to observed changes. } \\
\text { Functional evaluation of networks, i.e. appraise how } \\
\text { the network helps its members to work together. } \\
\text { Advantages of participatory action research methods } \\
\text { of evaluation: } \\
\quad \text { - Reveal intangible outcomes (can only be } \\
\quad \text { done by members) } \\
\quad \text { Stimulate members to reflect on their } \\
\quad \text { partnership } \\
\quad \text { Activity in itself } \\
\text { Activities will encourage "trust-relationship" by } \\
\text { stimulating collaborative actions related to shared } \\
\text { values. } \\
\text { Issue of low-level involvement of members related } \\
\text { to expected benefits and knowledge on how to } \\
\text { participate. } \\
\text { Most efficient structure consisting of elected steering } \\
\text { committee, coordinating secretariat and general as- } \\
\text { sembly for strategic choices. }\end{array}$ \\
\hline
\end{tabular}

with productive outputs were cited as highly valuable, like the annual organisation of an international conference, the publication of a charter on quality of medicine, or the creation of an e-tool for sexual and reproductive health and rights. Apart from the productive content of these activities, added value was reported through socialisation, trust-building, and learning to work in a network context as a capacity building in itself. As John points out:

\section{My main objective [...] is to meet people and to discuss ques-}

tions I would have. We can confront ideas, and this stimulates my "out-of-the-box" thinking and creativity. The more formal aspects and the actual content are less important.

$\mathrm{BCH}$ was considered as unique (Amy), with no national or international equivalent (Mike). As Mike formulates it:

The creation of this platform is in itself a great achievement [...] The first objective is to fertilise people, to feed them with ideas, and that seems very well achieved at $\mathrm{BCH}$. It is an op- 
portunity to meet with other members, exchange and benefit from each-other.

$\mathrm{BCH}$ allows members to know what is going on in the sector and inform their future decisions (Amy, Lisa, Mike). "It is a unique opportunity to meet your peers" (John). As Amy expressed it:

We are sharing, we are taking home some information and we know what others do. After each meeting, we come back with some goodies. The sharing part is crucial. We also try to define how we could, as a group, have an impact.

With a broader viewpoint, Lisa pointed out:

$B C H$ is the cement between the member organisations of the Belgian development sector. If you build a house, you need bricks, but you also need the cement to link them together.

In addition, the networking activity was clearly identified as an important linking factor, sometimes leading to new professional opportunities.

\section{Overall organisation}

Most interviewees were very positive about the overall organisation of the network (Lisa,John,Mike). There was a consensus to cite the annual conference as an example of a very well organised remarkable activity. For this event, international opinion leaders are invited as speakers around hot topics for development. Above all, the interviewees considered it as a trust-building activity that reinforced the collaboration inside the network.As Amy said:

Those [annual conferences] are very strong moments because there is a real synergy. All the people can bring in their own inputs and we can get out a lot of information. BCH has a face and a name and that is very important. We learn more about colleagues and we, as an organisation, can figure out how to contribute to what is happening in the sector.

All interviewees agreed the secretariat, in synergy with the steering committee, played a central role in the success of the network's activities.

Lisa insisted on the importance of having a paid secretariat: The presence of a secretariat with paid staff is important for the stability and the sustainability of the network's activities, because volunteers are volatile as well. Together with the steering committee, it's the central hub of the network. It's also essential for the secretariat to rely on a solid and wellorganised structure that can support its functioning. However, the financial and human resources of our secretariat are limited. The integration of $\mathrm{BCH}$ as part of a wider institution like ITMis essential to support the secretariat when extraordinary activities, like the annual conference, are organised.

Ben insisted on the supportive role of the secretariat:

It is holding all the strings in its hands, but these strings should not always be in tension. Its role is to support the members in their activities, not to control nor to participate directly.

In line with this quote, Lisa said the secretariat should not substitute itself to the TWG:

The secretariat should create a space where autonomy is given to the TWG instead of absorbing too much of their activity. They're more organisers, facilitators. Rather than cooking itself, the secretariat should create a space where others can cook.

Several of the participants reflected further on the responsibilities of the secretariat. Lisa, for example, reflected that:

It is essential [for the secretariat] to bring up relevant themes of activity. This can happen bottom-up, when members with a common interest are linked together, top-down, when the network is requested to analyse policy reports, or for internal reasons, for example when new members with a specific interest join the network. TWG have been created as a response to recommendations concluding the activities like the annual conference. In other cases, TWG arose from the general context. Some TWG responded to the policy advice or advocacy role of $B C H$, like preparation of policy documents, giving input to official documents.

The role of the secretariat as an information agent could be further improved, both internally and externally. Interviewees were not always aware of what was happening in other TWG (John,Mike). Mike pointed out:

In some meetings, we were thinking "Are there no other groups overlapping for some of the topics discussed here?", and I had the feeling [...] that we were not fully aware of what was happening in other groups.

Also, BCH does not come out sufficiently in the public media. There is a lack of visibility of the network. When BCH organises events like the annual conference, it should adopt a more persistent behaviour towards the media, so that they cover the event.

Ben said another essential role of the secretariat was to identify and to support motivated members:

The secretariat should look for champions, members who are willing to invest in the network and identify themselves with it. These motivated members should be supported in their leading role. 
Information exchange and discussion were considered an important outcome for $\mathrm{BCH}$, and this mostly happens inside the TWG (Lisa,Ben).TWG are also a useful tool for consensus building (Lisa):

Within networks with a great diversity as $\mathrm{BCH}$, consensus building amongst all the members is very laborious, often impossible nor even desirable. TWG allow a small group to work on a concrete product and offer it to the other members, who will eventually use it or support it. This is how the quality charter for medicines was created, and subsequently approved by the whole network.

The creation of TWG, with activities defined by the members tailored to their needs, is an important stimulant of involvement in the activities (Lisa). Amy suggests the formal organisation of the TWG could be reviewed towards more concrete results, for a more consistent implication of its members. While the secretariat should support their activities, the TWGs themselves need to bring up their own ideas (Amy):

The members of the TWG should come up with suggestions. They all come from different worlds, they have different ways to getting to a goal. The ideas should come from the troops, it shouldn't come from above.

Lisa added "It's counter-productive to force too much". The specific objectives of the TWG were not always clear, as well as who was really an active member of the group (John).

Some interviewees (Amy,Mike) had invested a lot of energy to contribute to some concrete output of the TWG but had the feeling their suggestions were not considered.

The chairman of the TWG was another key element of success (Amy,John,Ben), to clarify goals, stimulate participation and assign concrete tasks. The TWG thrive according to the context, and it could be perfectly justified for a group to enter a "sleeping mode" (Lisa):

A TWG will thrive when a group of people join their efforts to work on a common priority. When priorities change, it is perfectly justified for a TWG to enter a sleeping mode. It could text even be dissolved, but that never happens. There remains $a$ "thin blue line" keeping the group alive, which might be better than dissolving it. A lot of energy is necessary to create a group, and there are several examples of "revivals" when the momentum was there again.

\section{Membership criteria}

Membership criteria were considered important determinants of the representativeness of $\mathrm{BCH}$. Most interviewees (Amy, Lisa, John, Ben) highlighted the importance for $\mathrm{BCH}$ to stay an open network, considering it was important to make it easy for all to join, provided they agree with the vision, mission and values statement. Lisa:
An open network is needed for diversity, which is the key to stimulate the exchange of ideas and creative outcomes. Therefore, it is important for $\mathrm{BCH}$ to lower the barriers to membership. This is very different from a network with a strong advocacy goal, where membership should be more selective to reach a convincing consensus.

However, the involvement of the members, and what they could achieve together, was considered more important than their number. Lisa explained:

The members' involvement can vary with time, for example when changing employer or location, or when interested in other topics. With 469 members on paper, there is a need for more selective criteria.

Ben added:

The right balance should be sought between too many passive members and too strict rules, both being counter-productive. Strict rules and excessive formalisation can kill the dynamics.

Clear commitment from the members should be required, while keeping an open and wide membership (John,Ben). As Ben said:

It is easy and free to become a member, but involvement should be required in another way, through the time given for the network.

All participants considered the introduction of a membership fee would have a negative impact on the network. It might lead some valuable members to reconsider their affiliation, and it would require a deep revision of the network's legal status. They saw no clear benefit for the time being, as the network has a substantial core-funding at the moment.

\section{Control of the network and decision process}

All members of $\mathrm{BCH}$ can take part in the general assembly and vote to elect the members of the steering committee and its president. Rules have been established for gender balance, to guarantee a minimal representation of each language community (French and Flemish), and to make sure all types of organisations are represented (academic institutions, NGO's and public institutions and others). Democratic voting rules apply, and only two consecutive four-year mandates are allowed for presidency. The president cannot speak for all members to protect the diversity of the network.

For a network like $\mathrm{BCH}$, it is more important to have a consensus on the mode of functioning of the network, creating and facilitating the collaboration between its members, rather than to reach a consensus on the content itself (Lisa). $\mathrm{BCH}$ relies exclusively on public funding from the government, through a budget line of the Institute of Tropical Medicine in Antwerp (ITM). All participants considered this funding as 
legitimate. Ben:

Compared with the total budget of development aid, it is perfectly justified to spend this money to regulate the sector.

Lisa added:

$B C H$ has a real public utility, and it would not be appropriate to switch to private funding and let market mechanisms guide its functioning. It would bring up many more challenges, like budget issues and juridical status. Also, a lot more time would have to be dedicated in institutional issues instead of content.

The hosting role of ITM was considered a factor of stability.

The Belgian Development Aid Agency (Enabel) has also a strong influence on the network, through the involvement of its members and their proximity with the governmental decision-making level (Lisa). "These three institutions (Ministry, ITM, Enabel) have a predominant place in the network, and this quite naturally reflects their dominant position in the sector" (Amy, Lisa, Ben).

Ben reflected that:

This network provides a synergy between actors of development, creating a positive sense of proximity. Some of the members have another type of relationship outside the network, like funded NGOs and funding authorities.

This could also be a source of tension, certainly if competitive market rules are to be the new paradigm of the sector and if members consider themselves as competitors (Amy).

\section{Evaluation of the network}

The added value of the network needs to be documented (Ben). From the point of view of the funding authority, it is important to evaluate the impact of $\mathrm{BCH}$ (Amy). This is a difficult task, given the complexity of the environment and the unique nature of the $\mathrm{BCH}$ network, with important and hard to measure creative outcomes, arising from the dynamics it created (Amy). Ben stated that:

We need to start from the function of the network (linking, foster pluralism, cross-fertilisation). A combination of multiple methods might be the most appropriate evaluation:

-Quantitative measurements like the number of members, the list of activities, etc.

-Concrete stories like out-of-the-box elements or success stories. -Evidence of increased power and energy provided to the members, like opportunities to get involved in a topic at an international level.

John insisted $\mathrm{BCH}$ should not dedicate excessive time to the evaluation process:
We need to be careful not to dedicate too much energy for the evaluation and leave some time for the actual work. Most members know intuitively what should be improved.

All participants recognised the importance of evaluation, both for members and for external appraisal.

\section{Discussion}

The improvement of health equity is at the heart of the Because health network, a core value shared by all its members. This very diverse group of organisations and individuals pulls together because each one of them is actively striving to put the "Health for All" principle into practice. The network has been thriving continuously for more than a decade, and this sustainable growth is in itself an indication it is a conducive approach to the challenges its members are facing in the complex environment of health and development. However, it is important to evaluate the effectiveness of this networking activity, to support the ongoing public funding it requires, to strengthen members' involvement and to guide suchlike experiences of cooperation that could be transposed to other contexts. While there is no doubt an accurate evaluation is foundational to the improvement of the network structure, this is a challenging task for several reasons $[17,20]$. First, the health and development issues occur in a complex environment, and the contribution of the network is difficult to isolate from all other determinants. The $\mathrm{BCH}$ members are active in several projects all around the globe and their actions represent only a small proportion of the health interventions in these communities. Like pointed out by Church et al. [20], it would be unrealistic to measure $\mathrm{BCH}$ 's effectiveness through an evaluation of population health. Also, networks like $\mathrm{BCH}$ connect people, and these connections have creative outcomes which are difficult to measure [20]. If some authors [21] consider the outcomes of networking to be more important than the process of collaboration, one must bear in mind that collaboration has a value in itself,encouraging trust-building activities which can be the source of intangible outcomes [20]. This was clearly expressed by the interviewees, for which the main advantages of their membership were to connect with peers, to confront their views and to fertilize with new creative ideas. A participative approach of evaluation is necessary to account for these important outcomes of networking which can only be evaluated by the members themselves.

$\mathrm{BCH}$ is structured around an elected steering committee with a coordinating secretariat, and the general assembly of all members votes for strategic choices. This type of structure has been reported as adapted to networking activities, and associated with higher effectiveness $[19,20]$. Transparent democratic rules have been established by $\mathrm{BCH}$, and set up for trust relationships among members, as reflected in the interviews. In particular, the rules of representativeness for all groups of language, all types of organisations, and gen- 
der balance, are in line with the Belgian democratic culture and well appreciated by interviewees. Similarly, the rules of turn-over in leadership, the limited number of mandates of the president and the protection of diverse opinions, were considered as important factors of stability for $\mathrm{BCH}$.

The growth of $\mathrm{BCH}$ is a positive consequence of its adequacy to respond to the member's needs, but it can generate some fundamental issues. From its creation, $\mathrm{BCH}$ adopted open and inclusive membership criteria, and this was undoubtedly a significant factor of its development. For networks, the ability to recruit new members and the inclusion of main actors of the sector are important determinants of effectiveness $[18,19]$.

The downside of this diversity of members is that it is complex to reach a consensus for strong advocacy. This issue has been brought up recurrently inside $\mathrm{BCH}$ [9] and it was seldom possible for all to agree on a common statement that could be endorsed by the whole network. However, $\mathrm{BCH}$ could bring forth the creation of other networks that were more oriented towards advocacy. For instance, the QUAMED network was created as a spinoff of the TWG on quality of medicines [9], to allow a stronger and more independent activity on these issues.

The expansion of $\mathrm{BCH}$ might compromise its effectiveness. At some point, the network's size can increase inertia and be counter-productive, especially if a large proportion of the members are inactive. The involvement of members is a recurrent issue for networks, but there are very few data on its determinants [20]. A network is the product of its members. Their collective contribution to the network's activities and the personal benefit they obtain in return are closely interrelated, and both are strong determinants of the network's effectiveness $[\mathbf{7 , 1 7 , 1 8 , 2 0 ]}$. Trust-building, experience-sharing activities, are time-consuming, but they are important steps in the development of the network $[7,19]$. They are also associated with better long-term results than task-oriented activities [19]. However, concrete results are a motivating factor for the members' involvement $[\mathbf{7 , 1 9}]$, and this was clearly expressed by interviewees. For instance, the preparation of policy papers and the input the network could make to official documents, at national or international level, is a valued concrete activity.

The role of the secretariat is another key to effective networking activities [18-20]. The secretariat provides the logistic support to all activities, from the smallest meeting of a TWG to the organisation of the annual international conference. It also links members together and disseminates information, both within the network and externally. Importantly, the secretariat of $\mathrm{BCH}$ has always been in search for the right balance of support to the TWG, facilitating their activities without compromising their autonomy. Interviewees recognised the high value of the secretariat, and suggested it could encourage more concrete activities.

The workload of the secretariat is quite heavy, and the presence of paid staff is of cardinal importance for the continuity if the network. For the secretariat of $\mathrm{BCH}$, it is also highly valuable to be supported by the wider organisation of the institute of tropical medicine of Antwerp (ITM), certainly for the logistics and housing of the activities. The non-institutionalisation of $\mathrm{BCH}$ also unburdens the network from a large part of the accounting and legal aspects of being a formal and independent structure. The public funding affected to $\mathrm{BCH}$ through the ITM is its sole source of revenue, but this dependency was not perceived as problematic by the interviewees. Unlike $\mathrm{BCH}$, the issue of fundraising can be a major challenge for networking activities [18]. All interviewees recognised the value of this support and were not experiencing any barrier to their autonomy.

The people are the foundation of all networks, and it is important to allow strongly motivated members, often labelled as "champions", to blossom and inspire their peers [19]. One interviewee specified it was an essential duty of BCH's secretariat to identify champions and to support them in their leading role.

In their analysis of network performance, Keast and Mandell [17] defined a network typology now most commonly used as reference: cooperative, coordinative and collaborative network. Their root concept is that each networking activity has specific attributes, and requires a level of collaboration largely depending on its objectives [17]. Information sharing will only require a loose structure for what they define as a cooperative network. Its members have a positive attitude towards each other but without changing their individual goals. To achieve more concrete goals the members need to share some of their resources for joined actions in what is defined as a coordinative network. Ultimately, goals which can only be met together require a collaborative network with reciprocal interdependence of the members, undergoing a profound change in their own system. As revealed by the interviews, the $\mathrm{BCH}$ network does not fit only one of these specific categories, but it is highly flexible and adaptive to the level of collaboration needed. A subgroup might be in a cooperative mode of information sharing, while another TWG will be coordinative for concrete activity, and all are matching their level of partnership to the changing internal and external context.

Overall, these interviews illustrated the link between the sustainable growth of the $\mathrm{BCH}$ network and the capacities commonly reported as essential for successful partnership $[19,20]$ : clear goals, inspiring and creative leadership, adaptive functional flexibility, efficient management, good organisational skills and an organisational culture fostering trust among its members.

Interviews of selected members cannot be considered representative of the whole network. Interviewees are a very selective group of members willing to participate. The interviewing process included some prompting with data from the literature review. Every effort was made to allow the interviewees to express their views spontaneously before requesting their opinion on the data selected from the literature, but the interviewees' opinions might have been influenced.This was 
not considered problematic as it would ultimately allow the interviewees to consider and reflect on the transferability of these suggestions. It should not have restricted the range of structural changes to considerfor the $\mathrm{BCH}$ network. The combined data from the literature review and the interviews aimed to be as broad as possible to allow the network as a whole to perform the most comprehensive analysis of its structure.

\section{Conclusion}

Networks are considered a natural response to complex issues, but they require elaborated interactions. Their outcomes, largely creative and intangible, cannot be measured with straightforward quantitative method, and require participative methods of evaluation. There is no formula to predict the change of effectiveness that would result from a change of structure. Ultimately, the structure of a network shall be determined by its members, in function of their background, of the network's objectives and the particular context in which the network will be active. Some network structural features were recurrently mentioned in the literature and by the interviewees, like the central role of the members and their involvement, the support of the secretariat, the leadership and trust-building concrete activities. The evolution of the network for, hopefully, improved effectiveness and sustainability, is a continuous process. The $\mathrm{BCH}$ network was created as a joined initiative of the Belgian public authorities and the ITM, and is embedded in that larger institution. It has succeeded to mobilise an increasing number of very diverse actors around the central theme of health equity, as the cement between the member organisations of the Belgian development sector, coordinating the sector and strengthening its impact at national and international level. This study explores the growth of the $\mathrm{BCH}$ network, aiming to contribute to its development and to inspire the creation of similar partnerships in other contexts.

\section{List of abbreviations}

ALbD: Active Living by Design

$\mathrm{BCH}$ : Be-Cause Health

DGD: Directorate-General for Development Cooperation and Humanitarian Aid, a federal service part of the Belgian Ministry of Foreign Affairs, Foreign Trade and Development CASP: Critical Appraisal Skills Program

CHP: Community Health Partnerships

CSO: Civil Society Organisation

ENABEL: Belgian development aid agency

IC: Informed consent form

ITM: Institute of Tropical Medicine of Antwerp

LSHTM: London School of Hygiene and Tropical Medicine

NGO: Non-Governmental Organisation

PIS: Participant information sheet

TWG: Technical Working Group

Competing interests

The authors declare that they have no competing interests.
Authors' contributions

\begin{tabular}{|l|c|c|c|}
\hline Authors' contributions & SVS & DS & KG \\
\hline Research concept and design & $\checkmark$ & $\checkmark$ & $\checkmark$ \\
\hline Collection and/or assembly of data & $\checkmark$ & -- & -- \\
\hline Data analysis and interpretation & $\checkmark$ & -- & -- \\
\hline Writing the article & $\checkmark$ & -- & -- \\
\hline Critical revision of the article & $\checkmark$ & $\checkmark$ & $\checkmark$ \\
\hline Final approval of article & $\checkmark$ & $\checkmark$ & $\checkmark$ \\
\hline
\end{tabular}

Publication history

Editor: Nicola Shaw, Algoma University, Canada.

Received: 18-Aug-2019 Final Revised: 20-Sept-2019

Accepted: 11-Oct-2019 Published: 27-Oct-2019

\section{References}

1. Atkinson M. The Development of an Evaluation Framework for Partnership Working. Electronic Journal of Business Research Methods. 2005; 3:3-10. | Article

2. Alders $C$, Havenkort B and Van Veldhuizen L. Linking with farmers. Networking for low-external-input and sustainable agriculture London: Intermediate Technologies Publications. 1993.

3. Grills N, Kumar RP and Porter G. Networking between community health programs: a team-work approach to improving health service provision. BMC Health Services Research. 2014; 14:1-7. Doi: | Article

4. Hardy B, Hudson B and Waddington E. Assessing Strategic Partnership, The Partnership Assessment Tool. London: ODPM. 2003. I Website

5. Lasker RD, Weiss ES and Miller R. Partnership synergy: a practical framework for studying and strengthening the collaborative advantage. Milbank Q. 2001; 79:179-205. | Article | PubMed Abstract | PubMed FullText

6. van Bree L, Fudge N, Tuomisto JT and Brunekreef B. Closing the gap between science and policy on air pollution and health. J Toxicol Environ Health A. 2007; 70:377-81. | Article | PubMed

7. Kendall E, Muenchberger H, Sunderland N, Harris M and Cowan D. Collaborative capacity building in complex community-based health partnerships: a model for translating knowledge into action. J Public Health Manag Pract. 2012; 18:E1-13. I Article I PubMed

8. Be-Cause Health Annual Report. Antwerp. 2016. I Website

9. Simaeys B. Evaluation 2014 Be-Cause Health Final Report. Be-Cause Health website. 2014. I Pdf

10. Mandell $M$ and Keast R. Evaluating the effectiveness of interorganizational relations through networks. Public Management Review. 2008; 10:715-731. | Article

11. Jones L and Smyth R. How to Perform a Literature Search. Current Paediatrics. 2004; 14:482-488. I Article

12. Centre for Reviews and Dissemination. Systematic Reviews. York: York Uo. 2008. I Pdf

13. Critical Appraisal Skills Program (CASP). CASP Qualitative Research Checklist. Oxford: Healthcare OCfTV. 2007. I Pdf

14. Durand MA and Chantler M. Principles of Social Research. Second edn. London: McGraw-Hill. 2014.

15. Sandelowski M. Sample size in qualitative research. 1995; 18:179-183. | Article |

16. Miles M, Huberman A and Saldana J. Qualitative Data Analysis: A Method Sourcebook. Third edn. London: Sage Pubications. 2014.

17. Keast R and Mandell MP. Network performance: A complex interplay of form and action. International Review of Public Administration. 2014; 18:27-45. | Article

18. Woulfe J, Oliver TR, Zahner SJ and Siemering KQ. Multisector partnerships in population health improvement. Prev Chronic Dis. 2010; 
Van Steirteghem et al. Journal of Public Health Aspects 2019, http://www.hoajonline.com/journals/pdf/2055-7205-6-1.pdf

7:A119. | Article | PubMed Abstract | PubMed FullText

19. Baker EA, Wilkerson R and Brennan LK. Identifying the role of community partnerships in creating change to support active living. $\mathrm{Am}$ J Prev Med. 2012; 43:S290-9. | Article | PubMed

20. Church M. Participation, Relationships and Dynamic Change: New Thinking On Evaluating The Work Of International Networks. London: London UC. 2002. I Website

21. Page SB, Stone MM, Bryson JM and Crosby BC. Public Value Creation by Cross-Sector Collaborations: A Framework and Challenges of Assessment. Public Administration. 2015; 93:715-732. | Article

\section{Citation:}

Van Steirteghem S, Sakellariou D and Gyselinck K. Maximising the Effectiveness of Multi-Platform Networks in Health and Development: A Case Study of Be-Cause Health. J Public Health Aspects. 2019; 6:1. http://dx.doi.org/10.7243/2055-7205-6-1 